Reference: Biol. Bull. 169: 431-448. (October, 1985)

\title{
A NEW MODEL OF PODIAL DEPOSIT FEEDING IN THE SAND DOLLAR, MELLITA QUINQUIESPERFORATA (LESKE): THE SIEVE HYPOTHESIS CHALLENGED
}

\author{
MALCOLM TELFORD, RICH MOOI, AND OLAF ELLERS
}

Department of Zoology, University of Toronto, Ontario, Canada M5S IAI

\begin{abstract}
The feeding mechanism of Mellita quinquiesperforata (Leske) has been examined in detail. This sand dollar is a deposit feeder, ingesting particles mostly in the range of $100-250 \mu \mathrm{m}$. The particles are picked out of the substrate individually by specialized long barrel-tipped podia, which form a narrow palisade surrounding the geniculate spine fields on the oral surface. Selected food items are passed to short barrel-tipped podia, thence from podium to podium until they reach the food grooves where they are finally aggregated into mucus cords. The cords are passed to the mouth by the activity of food groove podia. At the peristome, the cord is passed between the circumoral spines by large food groove podia and steered into the mouth by five pairs of buccal podia. The lantern is powerfully muscled and has hardened teeth which crush diatoms and fracture many sand grains. For this reason, there is an apparent accumulation of fine particles $(<50 \mu \mathrm{m})$ in the gut. Analysis of size frequencies of the material in the mucus cords and substrate indicates that no selection of fine particles occurs and, in fact, that they are virtually absent from the native sediment. An account of spine and podial morphology and distribution is included with descriptions and measurements of surface ciliary currents. It is shown that the formerly accepted sieve hypothesis of feeding cannot be entirely rejected on theoretical grounds. However, during feeding there was no evidence of the operation of any of the elements of the supposed sieve mechanism. Furthermore, the ciliary currents are not fast enough to account for the movement of most ingested material. Patterns of ciliary flow on the oral surface are not simply centripetal, but are much more complex than previously supposed.
\end{abstract}

\section{INTRODUCTION}

The precise nature of the feeding mechanism in sand dollars has become a matter of some controversy. Two quite different mechanisms have been proposed. The first postulates that the aboral surface spines act as a sieve which selects small particles. The second postulates that podia of the oral surface are the primary food collecting organs. The sieve hypothesis originated in an account of Dendraster excentricus (Eschscholtz) by the McGinities (1949) and was presented, more or less in its present form, by Goodbody (1960) following a study of Mellita (Leodia) sexiesperforata (Leske). According to this hypothesis, fine organic and inorganic particles drop between the spines on the aboral surface. The particles are picked up in ciliary currents and swept around the ambitus (or via the lunules) to the oral surface, where they eventually enter the food grooves. Recent supporters of this hypothesis [Chia, 1969 for D. excentricus; Lane, 1977; Ghiold, 1979, Alexander and Ghiold, 1980, Lane and Lawrence, 1982,

Received 29 March 1985; accepted 30 July 1985.

'Address: Department of Zoology, Duke University, Durham, North Carolina 27706. 
Smith and Ghiold, 1982 for M. quinquiesperforata; Mooi and Telford, 1982, Ghiold, 1983 for Echinarachnius parma (Lamarck)] allowed, at most, a secondary role for podia in particle collection although they recognized a role in food transport. The podial mechanism for clypeasteroid feeding was espoused by Nichols (1959) and later by Telford et al. (1983) for Echinocyamus pusillus (O. F. Müller); by Ellers and Telford (1984) for Echinarachnius parma; some elements of it were described for $D$. excentricus by Timko (1976), and it is implied, but unstated, as a generality by Kier (1974). Mooi $(1983,1985 \mathrm{a}, \mathrm{b})$ has described an array of morphological differences in podia and podial distributions which can best be explained in light of the podial feeding hypothesis, although he and Telford (1982) had once inclined to the sieving hypothesis. According to the podial hypothesis, food particles such as diatoms, organic debris, or grains of sand laden with nutrients, are individually picked out of the substrate by podia and then passed from one podium to the next until they reach the food grooves.

It is a central tennet of the sieve hypothesis that the particles must be small $(<100$ $\mu \mathrm{m}$ ) in order to move through the interspine spaces and to be transported by ciliary currents. Major criticisms of the hypothesis (Ellers and Telford, 1984; Telford, 1983) have focused on the following points: (i) inclusion in the gut contents and the food cords of numerous particles too large to be accommodated by the sieve mechanism; (ii) unsuitability of the velocity and direction of ciliary currents as transport vehicles, and (iii) lack of direct observations and experimental data that provide adequate support. These criticisms have been based primarily on experience with the nonlunulate species, E. parma, and on evaluation of the published findings of other investigators. Most of the proponents of the sieve hypothesis have worked with lunulate sand dollars, most notably with $M$. quinquiesperforata, which might be quite different in their modes of feeding.

In this paper we provide a completely new description of anatomy and feeding in Mellita quinquiesperforata, including data on: spine types; ciliary currents; diversity, structure, and function of podia; and collection, transport, and ingestion of food. These observations show that podial selection is, indeed, the principal feeding mechanism. In addition, we will show how confusion with ciliary-borne material might have arisen.

\section{MATERIALS AND METHODS}

Specimens of $M$. quinquiesperforata were collected at Bird Shoal (Beaufort, North Carolina) in March 1984, and maintained in running seawater and natural substrate in the laboratory. Specimens ranging from $2 \mathrm{~mm}$ to $75 \mathrm{~mm}$ in diameter were used in this study. Some specimens were fixed in the field, immediately after collection. For SEM examination the fixative was $2 \%$ glutaraldehyde. For general histology and examination of gut contents, $10 \%$ buffered formalin in seawater was used. After fixation, specimens were stored in $3 \%$ neutral buffered formalin. Ten substrate samples, $20 \mathrm{~mm}$ deep and $50 \mathrm{~mm}$ in diameter, were collected from sites beside individual sand dollars and fixed in $10 \%$ buffered formalin to preserve living organisms and organic material. Larger samples were taken and kept fresh for use in the holding tanks and for feeding observations. Abundant supplies of diatoms were obtained in a plankton net towed in well-mixed, sediment-laden water near Bird Shoal.

Podia were classified according to the types described by Mooi $(1983 ; 1985 \mathrm{a}, \mathrm{b})$ and their distributions on the sand dollars were mapped. Similar maps of the distribution of the different types of spine were prepared. Spines were measured by ocular micrometer; inter-spine and inter-podial distances were estimated from live and freshly killed specimens. Distribution of cilia on different spine types was examined by light 
microscopy of isolated spines. Measurements of podia were made on live specimens, using an ocular micrometer, and supplemental measurements of tip dimensions were made from SEM micrographs of critical point dried material (Mooi, 1983).

Observation of live specimens in glass aquaria were made mostly with a stereoscopic microscope. The aboral surface could readily be viewed from above; the oral surface was examined with a horizontally mounted microscope and an inclined, front-silvered mirror or directly, using an inverted compound microscope. The same horizontal microscope was also suitable for study of the ambitus. Cold, fiber optic light sources were used for all observations. These methods were satisfactory for preparing detailed maps of ciliary currents, observation of spine and podial movements, as well as tracking individual food particles during feeding. Ciliary currents were made visible by fine streams of fluorescein in sea water, introduced from a microsyringe via a narrow tipped capillary tube. Tracer dyes disperse too rapidly for prolonged observation, for which finely ground carmine particles were used. Feeding was observed with a thin layer of substrate on the aquarium floor and was stimulated by offerings of sand enriched with diatoms obtained from plankton tows. Rates of ciliary currents and movements of particles were determined by stopwatch and ocular micrometer. At any single point, the currents vary considerably from time to time and are difficult to measure precisely. Our current velocity estimates are based on 5 to 10 determinations at each locality, and have an error of plus or minus $20 \%$.

Analyses of natural substrate (10 replicates), gut, and food groove contents (of 5 individuals) were made by counting particles. Very small samples of well-mixed material were strewn on microscope slides, all particles were drawn in outline by camera lucida, at least 500 were then measured and counted from each sample. Acid soluble carbonate was determined gravimetrically following digestion in $50 \% \mathrm{HCl}$. Diatoms were identified to genus (Griffith, 1961). For comparative purposes, freshly fractured sand grains were obtained by crushing between two microscope slides.

\section{RESULTS}

The following description of spination is from an adult animal. Spines grow with negative allometry, becoming relatively smaller as test diameter increases (Seilacher, 1979). Measurements given in Table I are for an individual, $75 \mathrm{~mm}$ in diameter. The aboral surface is covered by club-shaped spines (Fig. 1A) ("shoe" spines of Seilacher, 1979) with their expanded tips directed forwards in the anterior midline and diverging right and left on the sides. Towards the posterior the club spines gradually become oriented at right angles to the anterior-posterior axis of the test. Each club spine is surrounded by five or six miliary spines. The aboral miliary spines (Fig. 1B) are characterized by large sacs at the tips which fill in the spaces between the swollen tips of the club spines. Together, the miliary sacs and club spines form a complete canopy over the aboral surface. Beneath this canopy the spine shafts are approximately $100 \mu \mathrm{m}$ apart, although the exact distance in live specimens is constantly changing. Sacs were not included in the miliary spine measurements of Table I. Close to the lunules, the club spines show continuous variation in form, merging smoothly into the paddle-shaped lunule margin spines (Fig. 1C). Around the ambitus there is a fringe of larger spines (Fig. 1D). Ambital fringe spines increase slightly in length from anterior to posterior. On the oral surface the principal spine types are locomotory, geniculate, and pressure drainage channel spines. Locomotory spines (Fig. 1E) are arranged in narrow wedges in Lovén's interambulacra $1-4$ and as elongate patches posterior to the anal lunule in interambulacrum 5 (Fig. 3A). Anteriorly the locomotory spine patches of interambulacra 2 and 3 are united (Fig. 3A). Locomotory and ambital 
TABLE I

Lengths of different spine types $(\mu \mathrm{m})$ from one specimen of Mellita quinquiesperforata, $75 \mathrm{~mm}$ diameter

\begin{tabular}{llrr}
\multicolumn{1}{c}{ Spine type } & N & Mean & IS.D. \\
\hline \hline Anterior fringe & 20 & 2015 & 254 \\
Posterior fringe & 20 & 2367 & 352 \\
Locomotory & 20 & 1846 & 162 \\
Pressure drainage channel (pdc) & 25 & 1537 & 247 \\
Geniculate & 25 & 574 & 68 \\
Geniculate (among pdc spines) & 13 & 716 & 79 \\
Circum-oral & 15 & 1705 & 165 \\
Circum-anal & 16 & 2270 & 419 \\
Club & 34 & 690 & 36 \\
Aboral miliary & 32 & 605 & 32 \\
Oral miliary & 25 & 733 & 72 \\
Ant. lunule, fringe & 16 & 1481 & 285 \\
Ant. lunule, wall & 20 & 1458 & 225 \\
Ant. lunule, miliary & 25 & 691 & 68 \\
Anal lunule, fringe & 15 & 1692 & 243 \\
Anal lunule, wall & 20 & 1234 & 130 \\
Anal lunule, miliary & 24 & 568 & 45 \\
\hline
\end{tabular}

fringe spine types are somewhat alike in form and intergraded in size. Areas not covered by locomotory spines are mostly covered by geniculate spines (Fig. 1F). The shaft of geniculate spines is bent near the mid-point. These spines are oriented with their bent tips directed towards the interambulacra (Fig. 4) and pointing into the ciliary current flow (Fig. 5). They do not form interlocking baskets beneath the food grooves. In each ambulacrum there is a shallow depression with lateral tributaries. In ambulacrum III this depression expands gradually until it reaches the ambitus; in the other ambulacra the depressions continue smoothly into the lunules. These were called "food tracts" by Goodbody (1960) and "pressure drainage channels" by Telford (1983). The latter terminology (pdc) will be used throughout this paper. Within the pdc's, the spines (Fig. 1G) are longer and less bent than geniculate spines. They are much more widely spaced, and sparsely interspersed with miliary spines bearing small sacs on their tips. Elsewhere, scattered miliary spines may be encountered. Smaller versions of the pdc spines also occur on the inner walls of the lunules. Surrounding the mouth there are three tiers of straight, stout circum-oral spines (Fig. 1H). Around the anal papilla there is a cluster of longer anal spines (Fig. 1I). All spine types possess lengthwise bands of cilia on opposite sides of the shaft (Figs. 1A-I) and extending to different lengths along it. Ciliary currents flow at right angles to the ciliary bands. The orientation of ciliary bands depends more on the position of the spine on the test than on the shape of the spine itself.

Six morphologically distinct types of podia (Fig. 2A-F) can be recognized: (i) accessory; (ii) long barrel-tipped; (iii) short barrel-tipped; (iv) food groove; (v) large food groove; and (vi) buccal. Each is distributed in a characteristic, unique pattern (Fig. 3B). Accessory podia (Fig. 2A) are found in a discontinuous fringe around the ambitus. They are absent in interambulacra 2 and 3 where the locomotory spine fields extend to the ambitus, and at four isolated patches of locomotory spines anterior to ambulacra II and IV and also where the pressure drainage channel of ambulacrum III intersects the ambitus. The resting podia are shorter than the surrounding spines, but they are capable of extending to 5-6 $\mathrm{mm}$. The podial stem is very long, narrow, 




FIGURE 1. Spine types of Mellita quinquiesperforata. (A) club-shaped, (B) aboral miliary, (C) lunule margin, (D) fringe, (E) locomotory, (F) geniculate, (G) pressure drainage channel, (H) circum-oral, (I) anal. Spines in A-H are shown in two views, ciliary bands shown edge-on as a row of dots. Inset, J, is a crosssection through the peristome showing tiered arrangement of circum-oral spines. Stereom cross-hatched, peristomial membrane in solid black. All scale bars in $\mu \mathrm{m}$.

and flexible, terminating in a small, round, suckered tip (up to $100 \mu \mathrm{m}$ diameter) with sensory cilia. There is only a very narrow band of accessory podia fringing the aboral surface, with a few extending towards the lunules in the ambulacra. On the oral surface, between the locomotory spine fields, there are numerous barrel-tipped (b-t) podia. Barrel-tipped podia (Mooi, 1985b) have cylindrically expanded tips, approximately 


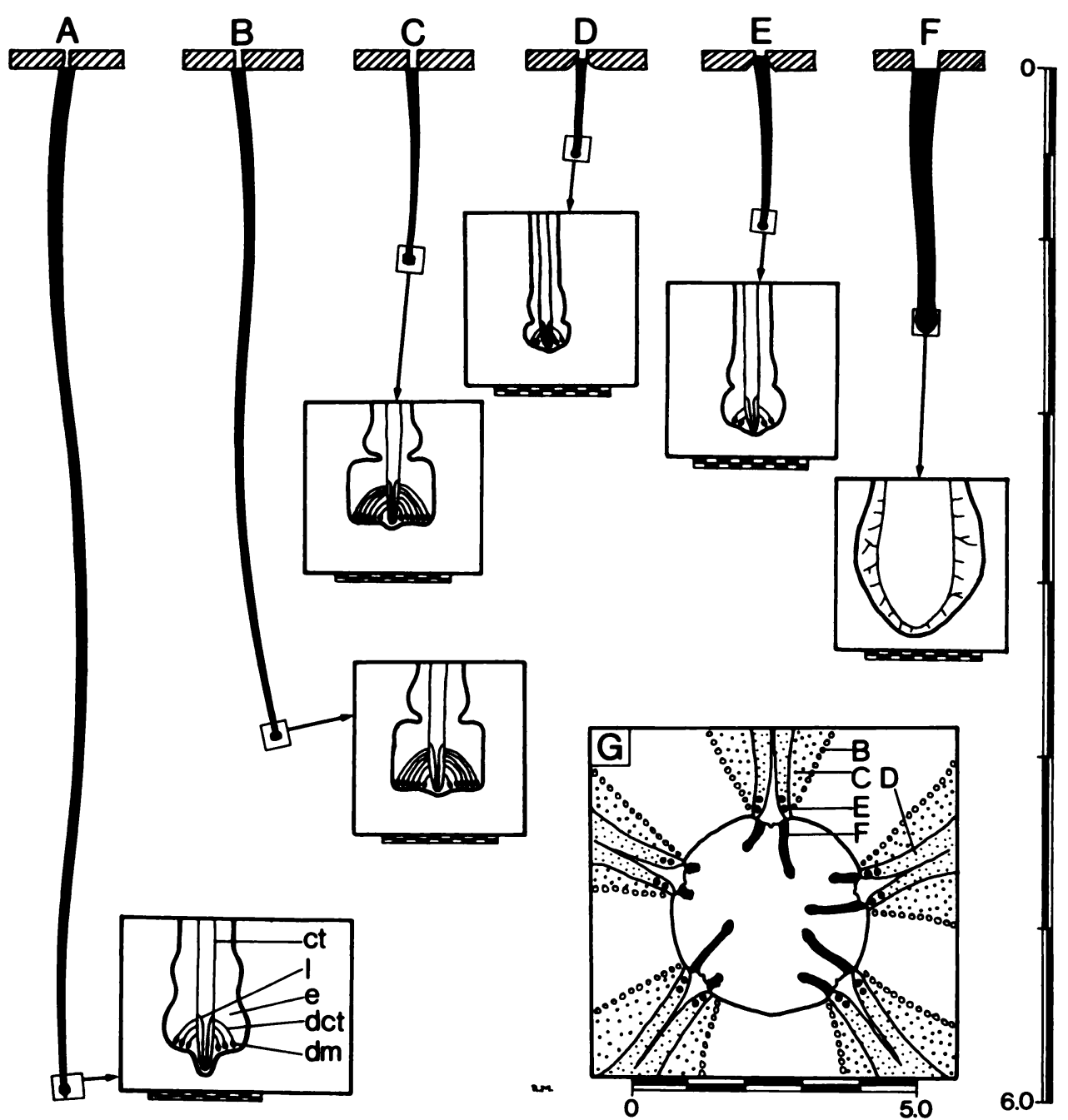

FIGURE 2. Podial types of Mellita quinquiesperforata. For A-F, podia in solid black are fully extended, scale bar at right in mm. (A) accessory, (B) long barrel-tipped, (C) short barrel-tipped, (D) food groove, (E) large food groove, (F) buccal. Each podium is accompanied by a close-up of the tip with accompanying scale bar of $100 \mu \mathrm{m}$. Structures are as labelled in A: c, connective tissue sheath; e, external epithelium; 1 , levator muscle; dct, disk connective tissue; dm, disk muscle. (G) shows arrangement of podia around the peristome, scale bar in $\mathrm{mm}$. Letters indicating podial types as in rest of figure.

$120 \mu \mathrm{m}$ in diameter (Fig. 2B, C). In M. quinquiesperforata there are two distinct forms, long and short. Long b-t podia are restricted to narrow strips (up to ten podial rows in width) along the edges of the pressure drainage channels and the locomotory spine fields. Thus they surround the geniculate spine zones. These podia can reach beyond the longest spines of the oral surface, a distance of some 3-4 mm. Short b-t podia have exactly the same distribution as the geniculate spines. They are less extensible and seldom reach $1 \mathrm{~mm}$ (less than the length of locomotory spines). In some clypeasteroid species there is also a distinction between large and small b-t podia (Mooi, 
A

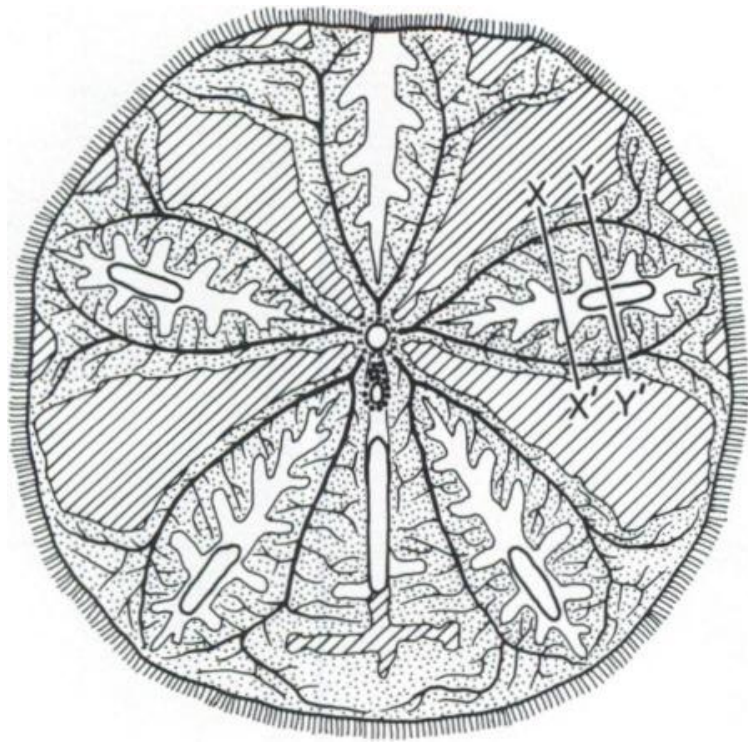

0

$5.0 \mathrm{~cm}$

B
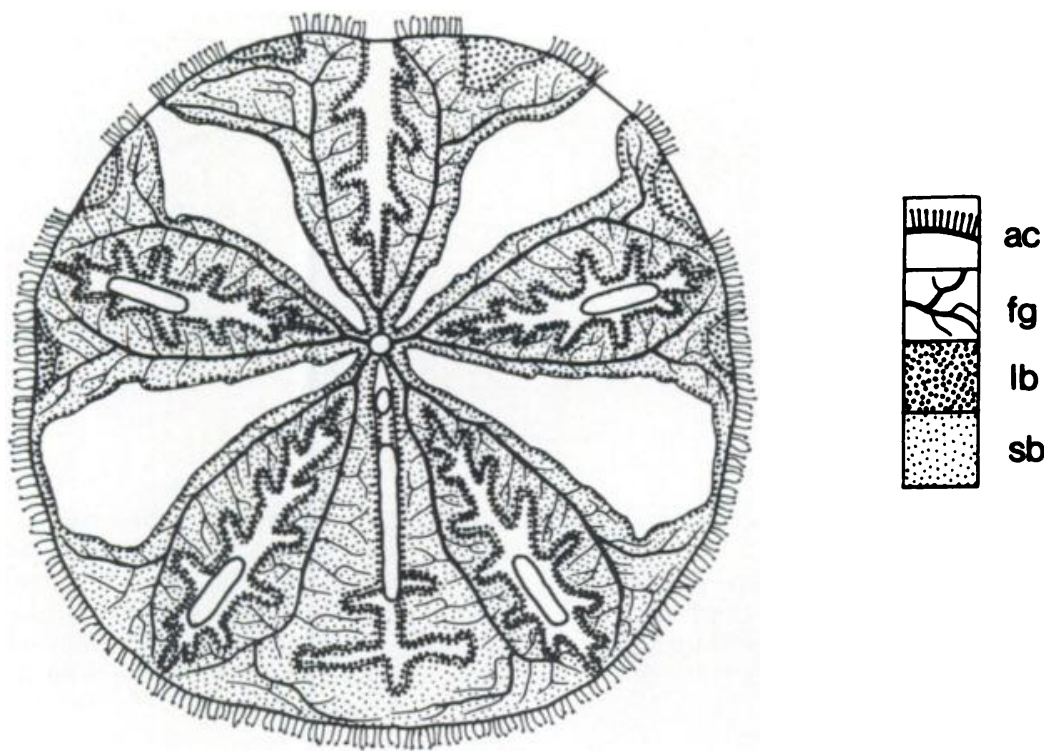

FIGURE 3. Distribution of (A) spines, and (B) podia on oral surface of Mellita quinquiesperforata. Transects $X X^{\prime}$ and $Y Y^{\prime}$ are shown in Figure 4. Spines: $f$, fringe; $g$, geniculate; l, locomotory; $p$, pressure drainage channel; c, circum-oral; a, anal. Podia: ac, ambital accessory; fg, food groove; lb, long barrel-tipped; sb, short barrel-tipped.

1985b), but this is not clearly apparent in $M$. quinquiesperforata. Other podial types are exactly as described by Mooi (1985a, b). The stubby food groove podia (Fig. 2D) are relatively inextensible, seldom reaching more than $0.5 \mathrm{~mm}$ in length and are confined to the walls and ceilings of the food grooves themselves. Close to the mouth large $(1 \mathrm{~mm}$ ) food groove podia (Fig. 2E) occur and, surrounding the mouth (Fig. 

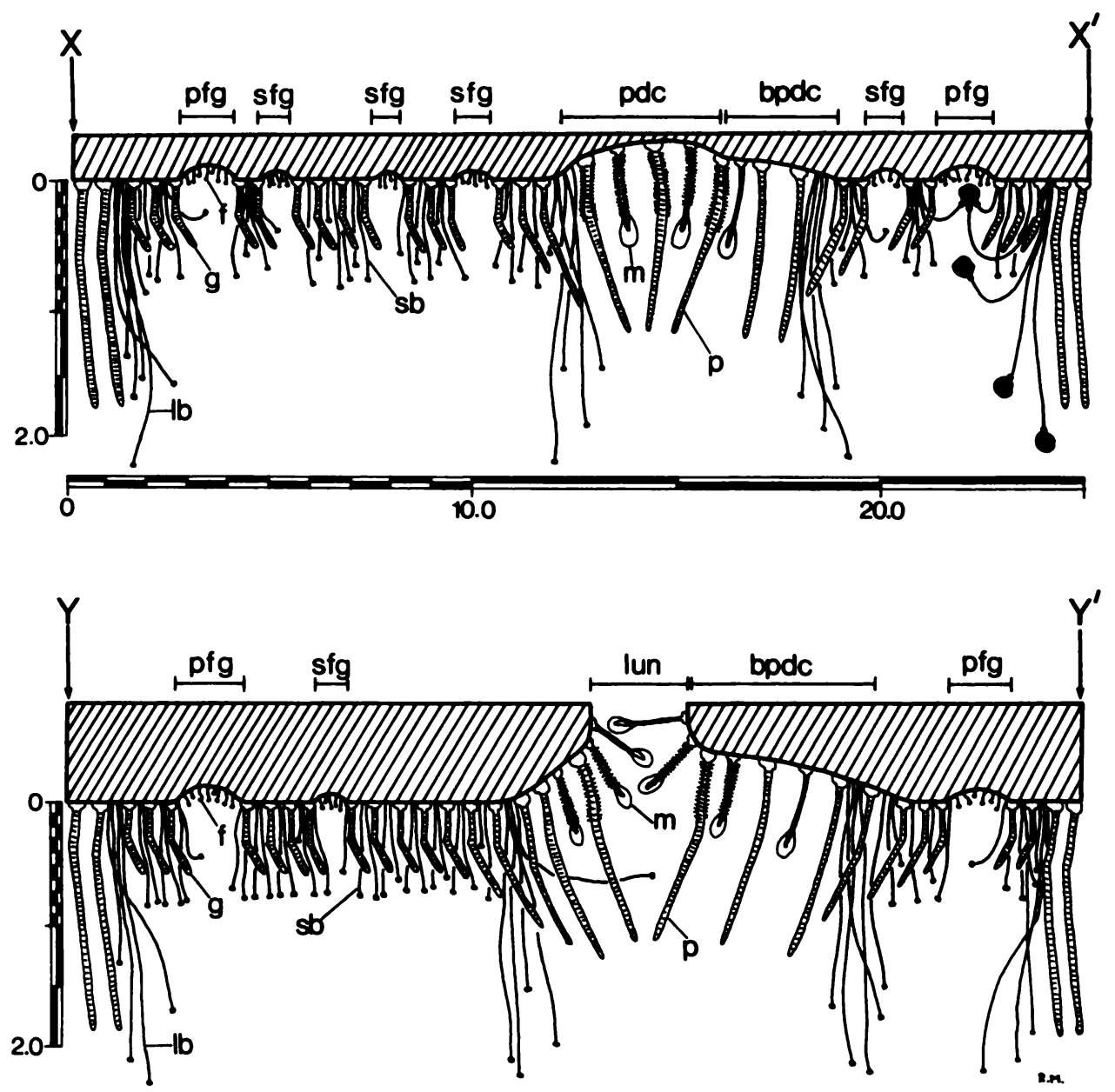

FigURE 4. Transects through oral ambulacrum of Mellita quinquiesperforata shown in Figure 3A. Scale bars in $\mathrm{mm}$. Vertical exaggeration $\mathrm{X} 3$ (except for lunule miliary spines). At right side of $\mathrm{XX}^{\prime}$ is a sequence showing long barrel-tipped podia collecting and placing substrate particle in food groove, aided by short barrel-tipped podium. bpdc, branch of pressure drainage channel; f, food groove podium; g. geniculate spine; I, locomotory spine; lb, long barrel-tipped podium; lun, lunule; $m$, miliary spine, $p$, pressure drainage channel spine; pdc, pressure drainage channel; pfg, primary food groove; sb, short barrel-tipped podium; sfg, secondary food groove.

2G), there are five pairs of buccal podia, $1.5 \mathrm{~mm}$ long (Fig. 2F) with bluntly rounded tips.

Currents powered by bands of cilia along the spine shafts occur between all spine types. Rates of ciliary flow are similar in the different spine fields $\left(0.8-0.9 \mathrm{~mm} \cdot \mathrm{s}^{-1}\right)$, but rates of particle movement may be different and depend on the spacing between spine shafts and podia (Table II). Velocities were estimated for particles 10 and $30 \mu \mathrm{m}$ in diameter because these sizes are common in gut contents and are in the size range favored by the sieve hypothesis. On the aboral surface the currents are centrifugal except at the margins of the lunules, where there is a very narrow region (comprising 
TABLE II

Velocities $\left(\mathrm{mm} \cdot \mathrm{s}^{-1}\right)$ of ciliary borne particles of $10 \mu \mathrm{m}$ (velocity 1) and $30 \mu \mathrm{m}$ (velocity 2) and inter-obstacle spacing ( $\mathrm{mm} \pm$ S.D.) in different regions of the surface of Mellita quinquiesperforata

\begin{tabular}{lcccc}
\hline \hline Spine field & Obstacles & Space & Velocity 1 & Velocity 2 \\
\hline Locomotory & L-L (20) & $0.46 \pm 0.087$ & & \\
& L-M (20) & $0.32 \pm 0.095$ & $0.85(9)$ & $0.60(9)$ \\
Geniculate & G-G (25) & $0.15 \pm 0.042$ & & \\
& G-P (25) & $0.05 \pm 0.021$ & $0.60(6)$ & $0.30(5)$ \\
PDC & S-S (25) & $0.40 \pm 0.085$ & & \\
& S-M (25) & $0.18 \pm 0.027$ & $0.70(7)$ & $0.70(7)$ \\
Ambitus & F-F (20) & $0.13 \pm 0.041$ & & \\
& F-P (20) & $0.04 \pm 0.023$ & - & \\
Aboral & C-C (34) & $0.20 \pm 0.044$ & & $0.64(8)$ \\
\hline
\end{tabular}

Obstacles: (i) Spine types: $L=$ locomotory; $G=$ geniculate; $M=$ miliary; $F=$ fringe; $C=$ club; $S=$ pdc spine. (ii) $\mathbf{P}=$ podium. Number of estimates of particle velocities are given in parentheses; all estimates were $\pm 20 \%$.

about 2-3 spine rows) in which the flow is diverted towards the lunules. At the ambitus the flow is both centrifugal and downward. On the oral surface the pattern of ciliary flow is much more complex than has been supposed by previous writers. Within the locomotory spine fields and the pdc's the flow is strongly divergent towards the adjacent geniculate spine fields (Fig. 5), but the center of the fields include a small centripetal component. Flow traverses the geniculate spine fields from the pdc side towards the locomotory spines, passing across the food grooves without interruption. At the junction between geniculate and locomotory spine fields (Fig. 5), the currents run directly into each other. As a result, both currents turn down towards the substrate. In contrast, at the junction between pdc and geniculate spine fields, some flow from the pdc enters the geniculate area and joins the flow towards the locomotory spines and some is deflected downwards (Fig. 5, inset). Towards the center there remains a slight centripetal flow which continues into the peristomial region. As elements of this flow converge beneath the mouth itself, they are united in a downward flow towards the substrate. The various downwardly directed flows are turned horizontally and, depending on the details of sediment contour, flow radially beneath the pressure drainage channels towards the lunnules and the ambitus (Fig. 5, inset). With an inverted microscope it is perfectly easy to see centripetal flow within the pdc spine fields and centrifugal flow beneath them. Locomotory movements of the spines and occasional "slumping" of the body (Lane, 1977) periodically interrupt the sediment surface flows so that outward flow via the lunules or at the anterior ambitus is, at best, intermittent. Indeed, periodically flow through the anal lunule may be temporarily reversed, water passing downward as the animal raises itself above the substrate.

Small particles caught in the ciliary flow on the aboral surface are carried to the ambitus, passing between the spine shafts. At the ambitus, many are lost simply by continuation of their centrifugal motion. A small number of particles pass around the ambitus and enter the oral surface currents. The bulk of this flow crosses the borders of the geniculate spine fields at some point, as described above. These spine fields are 

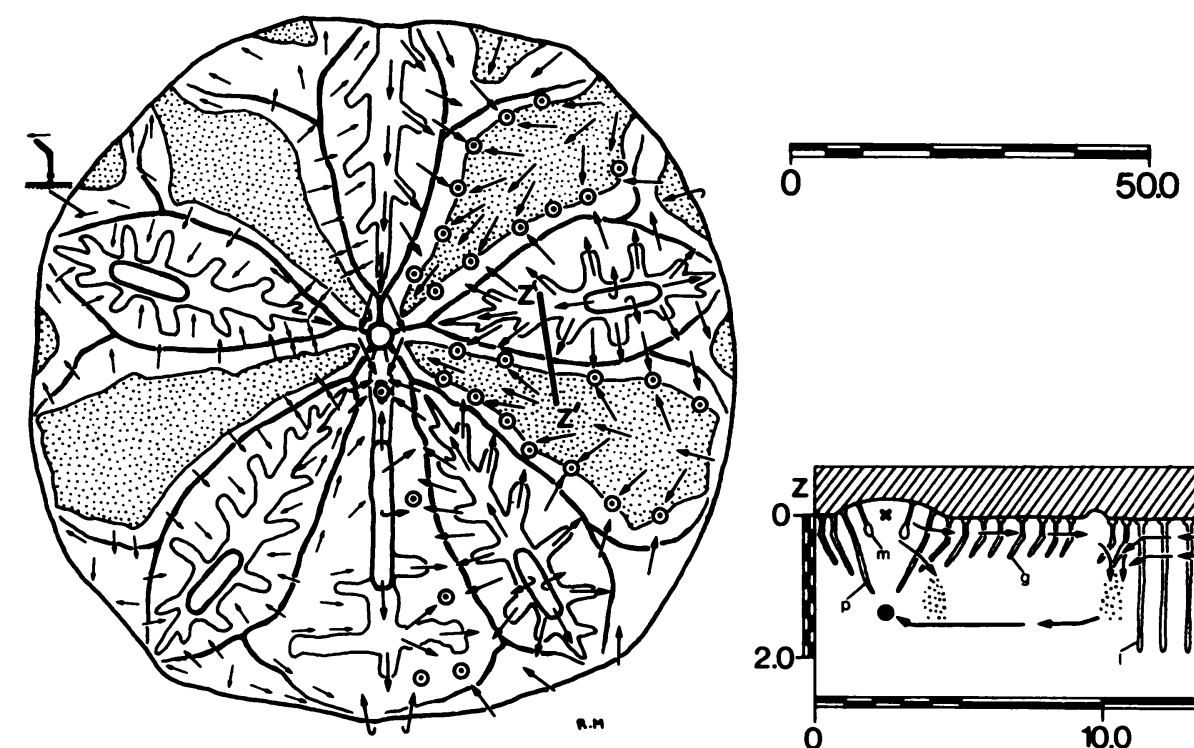

FIGURE 5. Ciliary currents on oral surface of Mellita quinquiesperforata. Larger arrows on right side of figure indicate direction of flow, dotted circles show meeting of currents resulting in particle dump sites. Smaller arrows on left side show direction of bend in geniculate spines (as indicated at upper left), locomotory areas stippled. Inset shows transect $\mathrm{ZZ}^{\prime}$. Crosses indicate flow into page, large dot indicates flow out of page (towards lunule), stipples represent deposition of particles. See text for further explanation. Spines: g, geniculate; 1, locomotory; $\mathrm{m}$, miliary; $\mathrm{p}$, pressure drainage channel. All scale bars in $\mathrm{mm}$.

bordered by long barrel-tipped podia, which occur nowhere else (Figs. 3B, 4). As the flow enters the bands of podia, it is slowed and directed downwards. The podia are richly supplied with mucus glands and suspended particles are rapidly trapped or dropped to the substrate. Those which are caught in mucus are often, but not always, incorporated in the streams of material sent to the mouth and eventually may be ingested.

Feeding was observed with natural substrate and with diatom enriched sediments. Unlike ciliary current flow, feeding is an intermittent activity. An individual may rest quietly for some hours and then feed rapidly for a few minutes, or possibly even for an hour or two. When animals are resting without feeding, no material passes along the food grooves. During these periods, fine particles caught in mucus are sloughed off. Feeding in $M$. quinquiesperforata starts when long barrel-tipped (b-t) podia pick up particles from the sediment. Long b-t podia of a sand dollar in its proper orientation collect particles, usually diatoms, diatom clumps or nutrient coated sand grains. Short b-t podia contribute little to the initial collection of particles. They function as the first stage in the transport mechanism, taking particles from the long b-t podia and passing them towards the food grooves, (Mooi, 1983; 1985a). During this process, particles are gradually coated with mucus secreted at the tips of the podia, and become increasingly adherent, so that, in the food grooves, they form well defined mucusbound cords. Food groove podia contribute substantially to the formation of the cords and are also responsible for their eventual transport to the mouth. Within 20 seconds of the start of feeding, cords have started down the food grooves to the mouth. As the cord advances, downstream food groove podia are stimulated into vigorous swinging. 
The average speed of the cords within the grooves is about $0.16 \mathrm{~mm} \cdot \mathrm{s}^{-1}$. Large food groove podia, absent in juveniles, are most readily identified in specimens $>20 \mathrm{~mm}$ in diameter. As the mucus cord approaches the rim of the peristome, the large food groove podia guide the strand between the circum-oral spines to the buccal podia, which in turn steer the entire cord into the mouth. No evidence of particle rejection was observed at the peristome, nor elsewhere. The feeding process could sometimes be initiated in a resting sand dollar simply by supplying diatom-rich material. Ambital accessory podia started exploring the material within a minute or so, picking up and discarding particles. The animal became more active and as the barrel-tipped podia contacted diatoms, food collection started. The accessory podia did not appear to be directly involved in selecting particles, neither are they another part of the transport system, their role appears to be primarily sensory. The overwhelming bulk of the collection was by the unaided long b-t podia. At no time during feeding did we see large diatoms carried in the ciliary currents and feeding was never initiated by fine particles supplied to the aboral surface.

The natural substrate of Bird Shoal is a very well sorted, medium to fine quartz sand with over $90 \%$ of the particles by number measuring $100-400 \mu$ m (mean 180.78 , S.D. \pm 59.74$)$. Only $8.7 \%$ of the particles were less than $100 \mu \mathrm{m}$. No statistically significant differences were found between replicates and the data were pooled (Fig. 6). Grains were angular to sub-angular, with a mean elongation (width/length) of 0.69 . Very little shell debris was observed. Acid soluble carbonate was estimated to be $<1 \%$ by weight. Several species of unattached diatom (Table III) were identified but they make up only a small fraction of the total number of particles $(\ll 1 \%)$. However, SEM and light microscopy showed that most of the sand grains support growths of smaller diatoms and were partially coated with organic material, as observed in other studies (e.g., Telford et al., 1983). During feeding, sand dollars select diatoms in greater proportion than their occurrence in the sediment. They rapidly picked out large diatoms when these were offered, and, although the ratio of diatoms to inorganic particles in our plankton enriched substrates was 1:4, in the food grooves between $90 \%$ and $100 \%$ of the particles were diatoms. Examination of the food groove material confirmed the high incidence of diatoms when sand dollars were feeding in native sediments. Otherwise, we were unable to detect any preference in the food material. Inorganic particles were collected in the proportions in which they occurred in the sediment (Fig. 6). Within the digestive system, very different proportions were found (Fig. 6): over 97\% of the particles by number were less than $100 \mu \mathrm{m}$. Analysis of variance shows that these differences are statistically significant $(P \ll 0.001)$ : the mean particle size in the gut is smaller and the distribution of sizes is different. In addition to broken diatom frustules, much of the gut material was sharp, angular sand granules, similar to those

TABLE III

Diatom forms, sizes, and relative abundance in sediment samples from Bird Shoal, North Carolina

\begin{tabular}{llll}
\multicolumn{1}{c}{ Form } & \multicolumn{1}{c}{ Genus } & Size, $\mu \mathrm{m}$ & Abundance \\
\hline \hline Centric, single & Actinocyclus & $100-175$ & Sparse \\
Triangular, single & Biddulphia & $75-125$ & Sparse \\
Centric, single & Coscinodiscus & $75-150$ & Abundant \\
Naviculoid, single & Rhaphoneis & to $150 \times 100$ & Common \\
Naviculoid, colonial & Striatella & to $80 \times 40$ & Common \\
Centric, colonial & Thalassiosira? & 50 & Common \\
\hline
\end{tabular}




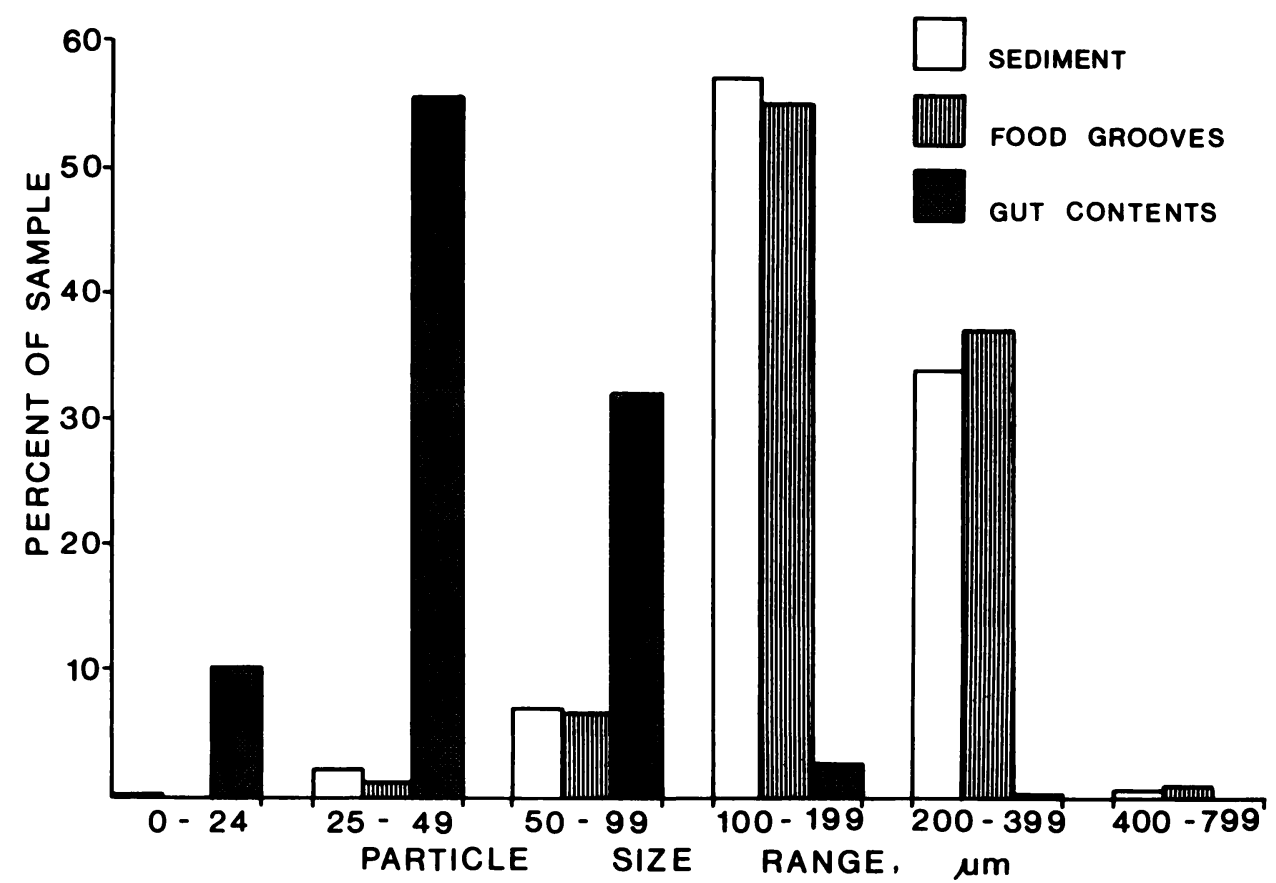

FIGURE 6. Percent composition of different particle sizes in the natural substrate, food grooves, and gut contents of Mellita quinquiesperforata.

from freshly fractured particles. Among the larger particles, we were able to identify many of the more common species of diatoms, including those shown in Table III.

\section{Discussion}

Since the work of McGinitie and McGinitie (1949) surface ciliary currents have featured prominently in explanations of feeding in clypeasteroids. Precise description and mapping is difficult because the currents are often quite feeble and subtle changes in direction are not always apparent under the microscope. Goodbody (1960) made no attempt to map the oral surface currents in $L$. sexiesperforata, stating only that they carried suspended particles to the food grooves. Only in the center of each locomotory spine field and each pressure drainage channel, is the flow centripetal. On either side of this, the flow is strongly divergent towards the geniculate spine fields. This departure from centripetal flow in M. quinquiesperforata has not been mentioned by previous investigators (such as Ghiold, 1979; Alexander and Ghiold, 1980; Smith and Ghiold, 1982). These writers described the flow as strictly centripetal. However, centripetal flow cannot terminate at the center, it must continue somewhere. The principle of continuity (see Vogel, 1981, inter alia) can most simply be understood as the common sense notion that if a volume (X) of water enters a pipe or system of pipes, then the same volume (X) must leave the system. In a continuous flow, the principle is expressed using flux which, for a single pipe, is the product of crosssectional area at the entrance and the average velocity of the entering fluid. The flux of fluid entering a system of many pipes is likewise equal to that leaving: 


$$
\sum_{\mathrm{i}}^{\mathrm{n}} \mathrm{S} 1_{\mathrm{i}} \cdot \mathrm{U} 1_{\mathrm{i}}=\sum_{\mathrm{j}}^{\mathrm{m}} \mathrm{S} 2_{\mathrm{j}} \cdot \mathrm{U} 2_{\mathrm{j}}
$$

where $S 1_{i}$ and $S 2_{j}$ are the input and output areas, respectively, and $U 1_{i}$ and $U 2_{j}$ are their respective velocities. The variables of summation, $\mathrm{i}=1$ to $\mathrm{n}, \mathrm{j}=1$ to $\mathrm{m}$, indicate the numbers of input and output pipes or channels. The complex series of spaces between the spines of sand dollars may be likened to the above system of pipes and this allows us to draw some important conclusions about ciliary flow. On the aboral surface, ciliary flow is centrifugal, at $0.8 \mathrm{~mm} \cdot \mathrm{s}^{-1}$. With increasing distance from the center, the perimeter, and hence the cross-sectional area of the flow, increases. Since the rate of flow is undiminished, the principle of continuity requires that more fluid enter the system. This is accomplished via the very small spaces between the miliary spine sacs and expanded tips of the club spines. Approaching the ambitus there is a narrow band of accessory podia between the spines, which effectively decreases the sectional area of flow. Accordingly, flow must either be accelerated or diverted. In practice, both responses can be observed: flow is diverted away from the test surface, i.e., a centrifugal component slightly upwards and outwards; at the same time, the downward flow between the spines is slightly accelerated. The extra half circlet of cilia on the bases of fringe spines, first observed in E. parma (Ellers and Telford, 1984), contributes to both increase in velocity and change in direction. The oral surface presents precisely the opposite situation: the perimeter, and hence cross-sectional area of flow, diminishes with proximity to the mouth, or center. Since the velocity of flow does not increase, it is clear that some flow must be diverted, it cannot be simply centripetal. Wherever streams converge, there must be a change in direction. Smith and Ghiold (1982) seemed to be aware of this when they claimed that water enters the mouth, swirls through the gut, exits via the anus and flows out through the anal lunule. We found no evidence to support this idea.

Our observations indicate that convergent currents occur in two situations: (i) a small residual centripetal current reaches the mouth region from the locomotory spine fields, and (ii) the principal flows out of the locomotory spine fields converge with currents moving across the geniculate spine areas (Fig. 5). The principle of continuity is satisfied because the system is three-dimensional: convergent currents are mutually deflected and united, downwards, towards the substrate. At the substrate surface the downward flow is again deflected, horizontally, and, depending on how the local sediment bed is shaped, flow becomes centrifugal towards the lunules and ambitus. The underside of $M$. quinquiesperforata is slightly concave and, in the natural habitat, this concavity is only partly filled with sand. The volume of this space is approximately 5-10 times the volume contained within the spine fields. Thus, when ciliary currents are directed downwards to the substrate surface and are no longer powered by cilia, they become much slower. Observation of the oral surface clearly shows that flow is brisk within the spine fields. Below the spines, flow is more sluggish, irregular, and sometimes in exactly the opposite direction. A similar situation prevails at the lunules, especially the anal lunule. Around the aboral rim, there is a downward flow within the spine field, and a gentle, occasionally intermittent or reversing, bulk flow upward, in the center of the lunule. The downward flow, within the lunular spine field, can only be drawn from close proximity to the rim (at most, 2-3 spine rows), without violating the principle of continuity.

Given the observed departures from centripetal flow, the bulk of the ciliary currents is directed towards the edges of the geniculate spine fields. Within these fields, flow is 
always away from the pressure drainage channels and towards the locomotory spines (Fig. 5). The geniculate spine fields are surrounded by a dangling curtain of long b-t podia. Flow from the pressure drainage channels is slowed among these podia, and deflected downwards, but it is not entirely stopped. Some flow continues into the geniculate field, actually crosses the food grooves, and unites with the current towards the locomotory spines. At the junction of geniculate and locomotory spine fields, the two flows collide. As described above, the flow is slowed, directed downwards and may become dispersed on the sediment surface. Suspended particles are brought by these flows to the long b-t podia and are dumped by the abrupt changes of direction and velocity. The long b-t podia are the principal food gathering structures. They are generously supplied with mucus and fine particles may adhere to them. Others, which fall to the substrate, may or may not be picked up later. Sometimes these fine particles became stuck to sand grains which were handled by podia, some of which were themselves dropped again. It is quite clear from our observations that some of this material, caught in mucus, can be incorporated into the food groove cords when the animals are actively feeding. However, it is obvious that much of it is lost during feeding. When the animals cease feeding, all ciliary-borne material is lost to the substrate because the podia are inactive and fully retracted within the spine fields.

Consideration of sinking rates and transit times also raises some doubt about the suitability of ciliary currents for feeding in sand dollars. The terminal velocity (U) of a spherical sinking particle far from walls can be derived from Stokes formula (see Vogel, 1981):

$$
U=\left[2 d^{2} g\left(\rho_{p}-\rho_{f}\right)\right] /(9 \mu)
$$

where $\mathrm{d}=$ particle diameter; $\mathrm{g}=$ acceleration due to gravity; $\rho_{\mathrm{p}}=$ density of the particle; $\rho_{\mathrm{f}}$ and $\mu=$ density and viscosity of the fluid medium, respectively. Assuming no wall effect, we estimate that a $10 \mu \mathrm{m}$ phytoplankter (density $1.067 \times 10^{3} \mathrm{Kg} \cdot \mathrm{m}^{-3}$; Vogel, 1981) would sink at $11 \mu \mathrm{m} \cdot \mathrm{s}^{-1}$, and that one ten times the diameter would sink at 100 times that rate $\left(1100 \mu \mathrm{m} \cdot \mathrm{s}^{-1}\right)$. If the ciliary stream is $500 \mu \mathrm{m}$ deep and flows at $0.8 \mathrm{~mm} \mathrm{~s}^{-1}$, then the $10 \mu \mathrm{m}$ particle would take an average time of 25 seconds to drop from the flow. During this time it would travel about $20 \mathrm{~mm}$ horizontally, enough to bring it into the b-t podial zones but not to the mouth of a moderately large sand dollar. The $100 \mu \mathrm{m}$ particle could travel an average of a mere $0.2 \mathrm{~mm}$ horizontally. Most ingested particles are sand, not plant cells, and their sinking rates are some 30-40 times greater. While this sort of estimate must be regarded with some reservation (sinking rates might be lower than this due to the proximity of spines), it appears unlikely that inorganic particles or large diatoms could be transported across the oral surface with the efficiency necessary for feeding. Therefore the only particles which might be transported by ciliary currents are small phytoplankters and we observed no evidence of their accumulation in the food grooves.

Many writers (Hyman, 1958; Bell and Frey, 1969; inter alia) have observed that $M$. quinquiesperforata spends periods in relative inactivity, without feeding. Our observations confirm that they feed intermittently, often with intervening hours of quiescence. When feeding starts there is a dramatic increase in spine and podial activity, the food grooves rapidly fill with mucus cords and material arrives at the mouth in two to three minutes. Considering the normally undemonstrative behavior of sand dollars, it is no exaggeration to describe this activity as a feeding frenzy! Ambital accessory podia extend to $5 \mathrm{~mm}$ or more around the margin, touching and exploring particles, picking them up, dropping them, or sometimes bringing them close to the 
body. These podia do not participate directly in food collection, they appear to be largely sensory (Mooi, 1983; 1985a). There is no systematic transfer of particls to place them on the aboral surface, nor within reach of the barrel-tipped podia. Food particles are picked up almost exclusively by the long $b-t$ podia and passed to the short b-t podia for transport to the food grooves.

The podial mechanism described here is totally unlike any previously proposed use of podia. In a recent review of clypeasteroid feeding mechanisms, De Ridder and Lawrence (1982) stated that: “. . . the accessory tube feet can stretch above [sic] the spines, probe the sediment, or directly pick up food particles (Goodbody 1960, Culver 1961, Bell and Frey 1969, Ghiold 1979)." It is worth examining this statement with two objectives: (i) to determine its observational basis and (ii) to follow the fate of particles so collected. Goodbody (1960) noted the movements of podia ". . . with no particles attached . . ." but, though able to work only at low magnifications (30X), he went on to assert: ". . . I believe that the function of these podia is to probe the sand for very small particles of food, i.e., particles of about $1 \mu \mathrm{m}$ diameter." Although clearly unable to observe this, he then said that such particles were released into centripetal currents and carried to the mouth. Goodbody has been cited as the authority for this ever since, and his exact words have been used in some instances. We are unable to comment on the contribution of Culver, cited above, because we have not seen his work (M. A. thesis, Duke University, 1961). Bell and Frey (1969) made some fortuitous observations on particle movements across the oral surfaces of four inverted sand dollars. Careful reading of their account shows that they saw podial involvement only in the food grooves. Elsewhere on the oral surface their description, which is vague, mentions only spines. So far as food collection was concerned (in contrast to its transportation) they frankly speculated: "The tube feet may also be important in the initial phase of food gathering, although this activity was not observed." In a somewhat superficial treatment of burrowing and feeding, Ghiold (1979) gave no hint of his methods. Ghiold says that his account is based on personal observations (unexplained) and those from the literature (citing Goodbody, Bell, and Frey). When he asserts that: ". . . the podia concentrated on the oral surface are continually probing the sediment for food," one can only assume that this was derived from Goodbody's similar description. Subsequently, Ghiold (Smith and Ghiold, 1982) has argued that: “. . . mellitids feed almost entirely on aborally derived material." This opinion has been shared by Lane (1977) and, more recently, by Lane and Lawrence (1982): “Mellita quinquiesperforata ingested the very fine particles that either fell on the aboral surface of the animal or were sorted from the sediment which covered its back. The oral and marginal surface and appendages (tube feet and spines) had no part in gathering food." Thus, in previous accounts we can find no clearly demonstrated role for the podia during feeding, except within the food grooves. Starting with Goodbody (1960), perpetuated by Ghiold (1979) and most recently by De Ridder and Lawrence (1982), there have been hints and suspicions about the activity of podia during feeding, but always inextricably linked with the sieve hypothesis. However, there has been a general tendency to discount podial activity in recent years, especially in the work of Ghiold and of Smith and Ghiold (cited above).

Diatoms, which are rare compared to mineral grains, are actively selected so that they become concentrated four or five fold in the food grooves. Most of the particles collected are sand grains which are taken in exact proportion to their occurrence in the sediment. The native sediment and food groove material have identical particle size distributions, and these differ greatly from the gut contents. Within the gut, a preponderance of small particles was reported by Goodbody (1960), Moss and Law- 
rence (1972), Lane (1977), and by Lane and Lawrence (1982), and has generally been interpreted as evidence of small particle selection by the sieve mechanism. In substrate samples collected at Bird Shoal, particles $<100 \mu \mathrm{m}$ made up only $9 \%$ of the total by number (Fig. 6), corresponding to less than $1 \%$ by weight. Lane (1977) reported higher proportions of small particles in her substrate samples, with approximately $10 \%$ by weight smaller than $125 \mu \mathrm{m}$. Within the gut of our sand dollars, $97 \%$ of the particles by number were $<100 \mu \mathrm{m}$ (approximately $65 \%$ by weight). Lane (1977) found a similar difference between gut contents and natural sediments, where, estimating from her data, about $62 \%$ of the gut contents by weight were $<62 \mu \mathrm{m}$. Kier (1974) observed that the gut of clypeasteroids usually contains "crushed" material. It is our contention that the lantern teeth actively break diatoms and sand grains into very fine particles. The lantern of clypeasteroids is large, heavily muscled, and has greatly hardened teeth (Kier, 1974). Most previous studies have neglected the role of the lantern in feeding. Lane (1977), however, asserted that the lantern was not involved and that: "No grinding or chewing functions were noted." (p 134). In contrast, in Echinocyamus pusillus, Telford et al. (1983) made direct observations of crushed material in the gut and scraping activity of the lantern, while Mortensen (1948), Kier (1974), and Mooi and Telford (1982) all observed crushed materials in the gut of other clypeasteroids. Furthermore, Timko (1976) specifically remarked that the teeth of D. excentricus ". . . thoroughly ground the food prior to swallowing." (p 252). Sediment particles broken between microscope slides yield fragments similar in size and shape to those seen in the gut. Sand grains are inherently weakened by minute fracture planes so that even the energies involved in inter-grain collisions during wind or water transport can be sufficient to break them into smaller sizes (Leeder, 1982). We suggest that the force delivered by the tips of the lantern teeth is at least equal to this. According to Leeder (1982) particle fracture in transit is negligible in grains below $50 \mu \mathrm{m}$ because collision energies are too low. The virtual absence of particles below this size at Bird Shoal is due to continual stirring by wave action and winnowing by local currents. The frequent occurrence of crushed diatoms in the gut of clypeasteroids suggests that exposure of their contents to digestive secretions may be the principal purpose of lantern activity, and that sand grains might only be fractured incidentally.

Surface ciliary currents are ventilatory and cleansing in function. Mellita quinquiesperforata occurs in clean, medium grained sands and is intolerant of finer particles (Weihe and Gray, 1969). Undoubtedly, some material swept from the surface in ciliary currents is incorporated in the food streams. However, experiments with carmine particles yield very misleading results. Sand dollars live in sediments with low organic contents. When carmine particles are used to track ciliary currents, they are applied in amounts far exceeding the natural occurrence of organic matter of that particle size. Observations of the underside of sand dollars, even when buried, show that the surface is perfectly free of fine particulate material: there is none adhering to spines and podia. When carmine is added, the podia rapidly become entangled in mucusbound particles. This is so different from the natural condition that it must be regarded with the utmost caution. In our opinion, it does not represent the manner in which small particulate matter is dealt with in feeding, nor do ciliary currents make a significant contribution to this process.

In summary, our observations show conclusively that food material is collected by oral surface podia. We cannot categorically rule out the inclusion of ciliary borne particles, but we are of the opinion that ciliary currents ventilate and keep the surface free of particles and, in so doing, make at most a trivial contribution to feeding. We are persuaded that the proponents of the sieve hypothesis have mistaken the cleansing 
activity for feeding, and have never witnessed the real process of food collection at all. We now challenge all "sievists" to provide convincing data in support of their hypothesis. Despite suggestions to the contrary (Ghiold, 1979; Lane and Lawrence, 1982; and others), we have found no evidence that the spines of $M$. quinquiesperforata secrete mucus. Our direct observations support the functional explanation of the histology, diversity, and distribution of podial types, described in detail by Mooi (1985a, b). The podial mechanism of feeding proposed here is strikingly like that of other clypeasteroids recently examined, for example Echinarachnius parma (Ellers and Telford, 1984), Echinocyamus pusillus (Telford et al., 1983) and, to some extent, Dendraster excentricus (Timko, 1976). Finally, this account of feeding provides a role for the large and well developed lantern which, under the sieve hypothesis, has been assigned no function in feeding.

\section{ACKNOWLEDGMENTS}

This work has been supported by the Natural Sciences and Engineering Research Council of Canada, through Operating Grant \#A 4696. We are indebted to the Director and Staff of the Duke University Marine Laboratory, Beaufort, NC, for use of their facilities. We also thank our colleague, Tony Harold, for many stimulating discussions and criticisms.

\section{LITERATURE CITED}

Alexander, D. E., AND J. GhiOlD. 1980. The functional significance of the lunules in the sand dollar, Mellita quinquiesperforata. Biol. Bull. 159: 561-570.

BELL, B. M., AND R. W. FREY. 1969. Observations on ecology and the feeding and burrowing mechanisms of Mellita quinquiesperforata (Leske). J. Paleontol. 43: 533-560.

CHIA, F. S. 1969. Some observations on the locomotion and feeding of the sand dollar, Dendraster excentricus (Eschscholtz). J. Exp. Mar. Biol. Ecol. 3: 162-170.

DE RIDDER, C., AND J. M. LAWRENCE. 1982. Food and feeding mechanisms: Echinoidea, Pt. 2: Irregularia. In Echinoderm Nutrition, M. Jangoux, and J. M. Lawrence, eds. A. A. Balkema, Rotterdam. 700 pp.

Ellers, O., AND M. TELFORD. 1984. Collection of food by oral surface podia in the sand dollar, Echinarachnius parma (Lamarck). Biol. Bull. 166: 574-585.

GHIOLD, J. 1979. Spine morphology and its significance in feeding and burrowing in the sand dollar Mellita quinquiesperforata (Echinodermata: Echinoidea). Bull. Mar. Sci. 29: 481-490.

GHIOLD, J. 1983. The role of external appendages in the distribution and life habits of the sand dollar Echinarachnius parma (Echinodermata: Echinoidea). J. Zool. 200: 405-419.

GOODBODY, I. 1960. The feeding mechanism in the sand dollar, Mellita sexiesperforata (Leske). Biol. Bull. 119: 80-86.

GRIFrTTH, R. E. 1961. Phytoplankton of Chesapeake Bay. Hood College Monograph \#1. Frederick, Maryland. Contribution \#172, Chesapeake Biological Laboratory.

HyMAN, L. H. 1958. Notes on the biology of the five-lunuled sand dollar. Biol. Bull. 114: 54-56.

KIER, P. 1974. Evolutionary trends and their functional significance in the post-Paleozic echinoids. J. Paleontol. 48 (suppl) Paleontol. Soc. Mem.: 5: 1-95.

LANE, J. M. 1977. Bioenergetics of the sand dollar, Mellita quinquiesperforata (Leske, 1778). Ph.D. Dissertation, Department of Biology, University of South Florida, Tampa.

LANE, J. M., AND J. M. LAWRENCE. 1982. Food, feeding and absorption efficiencies of the sand dollar, Mellita quinquiesperforata (Leske). Estuarine Coastal Shelf Sci. 14: 421-431.

Leeder, M. R. 1982. Sedimentology: Process and Product. George Allen and Unwin, London. 344 pp.

MCGINITIE, G. E., AND N. MCGINITIE. 1949. Natural History of Marine Animals. McGraw-Hill, New York. $437 \mathrm{pp}$.

Mool, R. 1983. Morphology, diversity and function of non-respiratory podia of clypeasteroids (Echinodermata: Echinoidea). M.Sc. Dissertation, Department of Zoology, University of Toronto, Ontario.

MoOI, R. 1985a. Non-respiratory podia of clypeasteroids (Echinodermata, Echinoidea): I. Functional anatomy. Zoomorphology (in press). 
MoOI, R. 1985b. Non-respiratory podia of clypeasteroids (Echinodermata, Echinoidea): II. Diversity. Zoomorphology (in press).

MOOI, R., AND M. TELFORD. 1982. The feeding mechanism of the sand dollar Echinarachnius parma (Lamarck). Proc. Int. Echinoderms Conf. Tampa Bay (1981): 51-57.

MORTENSEN, T. 1948. A Monograph of the Echinoidea. IV. 2. Clypeastroida. C. A. Reitzel, Copenhagen. $471 \mathrm{pp}$.

Moss, J. M., AND J. M. LAWRENCE. 1972. Changes in carbohydrate, lipid and protein levels with age and season in the sand dollar Mellita quinquiesperforata (Leske). J. Exp. Mar. Biol. Ecol. 8: 225-239.

Nichols, D. 1959. The histology and activities of the tube-feet of Echinocyamus pusillus. Q. J. Microsc. Sci. 100: 539-555.

SeILACHER, A. 1979. Constructional morphology of sand dollars. Paleobiology 5: 191-221.

SMITH, A. B., AND J. GHIOLD. 1982. Roles for holes in sand dollars (Echinoidea): a review of lunule function and evolution. Paleobiology 8: 242-253.

TELFORD, M. 1983. An experimental analysis of lunule function in the sand dollar, Mellita quinquiesperforata (Leske). Mar. Biol. 76: 125-134.

TELFORD, M., A. S. HAROLD, AND R. MOOI. 1983. Feeding structures, behavior and microhabitat of Echinocyamus pusillus (Echinoidea: Clypeasteroida). Biol. Bull. 165: 745-757.

Timko, P. L. 1976. Sand dollars as suspension feeders: a new description of feeding in Dendraster excentricus. Biol. Bull. 151: 247-259.

VogeL, S. 1981. Life in Moving Fluids. Willard Grant Press, Boston. 352 pp.

WEIHE, S. C., AND I. E. GRAY. 1969. Observations on the biology of the sand dollar Mellita quinquiesperforata (Leske). J. Elisha Mitchell Sci. Soc. 84: 315-327. 